Article

\title{
Good Deaths: Perspectives on Dying Well and on Medical Assistance in Dying at Thrangu Monastery Canada
}

\author{
Jackie Larm \\ Independent Researcher, Vancouver, BC, Canada; jcllarm@yahoo.ca
}

Received: 1 December 2018; Accepted: 17 January 2019; Published: 22 January 2019

\begin{abstract}
Anthropological, sociological, and bioethical research suggest that various agencies affect one's relationship with the dying process and end-of-life decisions. Agencies include the media, medical professionals, culture, and religion. Observing the prevalence of meditations and rituals relating to death at Thrangu Monastery Canada, I wanted to investigate how the latter two agencies in particular, namely culture and religion, impacted the monastery members' views on the dying process. During 2018 interviews, I asked their opinions on the meaning of dying well, and on Medical Assistance in Dying (MAID), which was legalized in Canada in 2016. Although some scriptural examinations have suggested that voluntary euthanasia is contrary to Buddhist teachings, the majority of the monastery's respondents support MAID to some degree and in some circumstances. Moral absolutes were not valued as much as autonomy, noninterference, wisdom, and compassion.
\end{abstract}

Keywords: Tibetan Buddhism; Canada; Euthanasia; Medical Assistance in Dying; Bioethics; good deaths; culture and religion in end-of-life decisions

"My life ends, this breath ceases, this body becomes a corpse, and this mind has to wander in different places."

\section{-From Gampopa's Jewel Ornament of Liberation (Gampopa 1998)}

I've watched a lot of Golden Girls in my time. In one episode, while facing an unidentified illness, Dorothy (Bea Arthur) asks her physician neighbour, "Harry, am I going to die?" He answers, "Sooner or later, I guarantee it!" Like Dorothy in the Golden Girls, I too have been told that I will someday die. Unlike Dorothy, however, these were not words from a medical physician; they were from Tibetan Buddhist teachers instructing me to consider my own mortality. As a follower of the 9th Thrangu Rinpoche and a member of Thrangu Monastery Canada (TMC) in Richmond, BC, the inevitability of death and the impermanent nature of all composite phenomena was one of the earliest contemplations I was assigned. The preliminary or foundational practices (Tib. Ngöndro) include the "Four Thoughts that Turn the Mind", one of which is the following meditation:

The world and living beings are transient,

Especially my life, like a water bubble-

Who knows when I will die and become a corpse?

Since Dharma will help then, I'll practice diligently. (Jamgön 2014)

Contemplations on death, it is believed in Tibetan Buddhism, reduce a person's attachment to temporary pleasures (and subsequently aversion to unwanted objects or occurrences), motivate one to engage more deeply with the buddhadharma, and prepare a person for his or her's inevitable death. 
Anthropological, sociological, and bioethical research suggest that various agencies affect one's relationship with the dying process and end-of-life decisions. Agencies include the media (like the Golden Girls in my case), medical professionals, culture, and religion (Howarth and Jefferys 1996; Barnes 1996). Observing the prevalence of meditations and rituals relating to death at Thrangu Monastery Canada, I wanted to investigate how the latter two agencies in particular, namely culture and religion, impacted other monastery members' views on the dying process. During 2018 interviews, I asked their opinions on the meaning of dying well, and on Medical Assistance in Dying (MAID), which was legalized in Canada in 2016. Results revealed to what degree members balance their values of individual autonomy, social harmony, compassion, and wisdom with the Vinaya, one of the scriptural authorities on Buddhist ethics.

\section{About Thrangu Monastery Canada}

Thrangu Monastery Canada describes itself as the first traditional Tibetan Buddhist Monastery built in the Pacific Northwest (Thrangu Monastery Canada 2018). Completed in 2010 along Richmond, BC's "Highway to Heaven", it is home to seven resident monks, including the Monastery's Director and Abbot, Dungse Lama Pema, and its head scholar Khenpo Sonam. ${ }^{1}$ The Monastery provides daily, weekly, monthly, yearly, and one-off Tibetan Buddhist ritual/prayer sessions, and classes in Tibetan ritual arts, language, and Buddhist philosophy at least once a week. According to Thrangu Rinpoche, the Monastery was built to provide a space for genuine Buddhist teachings to be disseminated and practiced (with the latter being the key), in the hopes that all sentient beings and the natural environment will reach a state of peace ${ }^{2}$ (Thrangu Monastery Canada 2018). The philosophical and ritual liturgical instruction its teachers provide generally belongs to the Karma Kagyu lineage of Tibetan Buddhism, which is, according to adherents, headed and embodied by H.H. the 17th Gyalwang Karmapa Ogyen Trinley Dorje. ${ }^{3}$ Thus, texts from the traditionally accepted Karma Kagyu canon are taught and Karma Kagyu prayers are performed throughout the year. However, since its Grand Opening in 2010, the Monastery has hosted Tibetan teachers from other lineages (such as H.H. the Sakya Trichen and Nyingma scholar Khenpo Tsultrim Lodro), as well as non-Tibetan teachers (such as popular Taiwanese monk Master Hai Tao). So, while the monastery is not pan-Buddhist and does remain lineage specific, it has not excluded instruction from teachers from other Buddhist traditions.

The Monastery is connected to the V.V. 9th Khenchen Thrangu Rinpoche's 40+ meditation centres, study groups, schools, monasteries, and nunneries worldwide. However, at the time of writing, Thrangu Monastery Canada was Thrangu Rinpoche's largest centre outside of Asia, both in terms of its physical size and in terms of the number of regular members and sponsors it has. This $35,000 \mathrm{ft}^{2}$ monastery is situated on two acres of land, most of which remains within the province's Agricultural Land Reserve. Thus, a portion of the organization's land is dedicated to farming; the monastery has a mixed orchard with approximately 160 fruit trees and shrubs, and six polyhouses in which vegetables and flowers are grown.

Thrangu Rinpoche is the uncontested leader of all of his centres around the world, but daily affairs at each of these centres are managed by appointees or volunteers. He appointed Dungse Lama Pema, a monk from Nepal, and one of his devotees, to be his North American representative in 2004 and to be abbot of Thrangu Monastery Canada in 2010. In addition to Lama Pema's teaching and ritual responsibilities, he determines the Monastery's program, deciding which ritual prayers (Skt. puja) will be done and which teachings will be given throughout the upcoming year. I would

1 Richmond's No. 5 Rd has been nicknamed the "Highway to Heaven" because of the significant number of religious institutions that line three kilometers of the road. Included are a Sikh Gurdwara, two Vedic centres, two Buddhist centres originating from Taiwan, Thrangu Monastery Canada, a Jewish Day School, two evangelical churches, and two mosques.

2 Thrangu Rinpoche, during an informal talk given to members, June 2018.

3 There was and is controversy surrounding the identification of the 17th Gyalwang Karmapa. Thus, some Karma Kagyu institutions and practitioners recognize another individual, Trinley Thaye Dorje, as the true Karmapa and head of the lineage. 
argue that, through his particular teaching style and the programs he has selected for the community, Lama Pema has shaped the general direction, especially of religious affairs, at Thrangu Monastery Canada. Lama Pema has stated that all of his (Buddhist) activity is done for his root teacher, the V.V. 9th Thrangu Rinpoche, and that he tries to remain consistent and adherent to the model of behaviour and comportment demonstrated by Thrangu Rinpoche. ${ }^{4}$ Lama Pema and the organization's additional board of directors remain in direct and regular communication with Thrangu Rinpoche himself and with Thrangu Rinpoche's Asian centres.

Thrangu Monastery Canada's community members come from a variety of cultural heritages. However, it is estimated that over $80 \%$ of regular attendees and volunteers (attendance $>/=$ once/week) are Chinese, reflecting both the popularity of Tibetan Buddhism among Chinese people in Richmond as well as this Canadian city's particular ethnic constitution. According to the 2016 Census, $76.3 \%$ of the population is a visible minority. The predominant visible minority group is Chinese; at $53-54 \%$ of the total population, this is the highest proportion of Chinese people in all of Canada. The next most common minority group is the South Asian group, at $7.3 \%$. In addition, $34.8 \%$ reported their ethnic origin as being Canadian, English, French, German, Scottish, or Irish. ${ }^{5}$ People from each of these ethnic groups attend the monastery's teachings and events, but the monastery's Chinese members are undoubtedly the most numerous. However, I would stress that at Thrangu Monastery Canada, the Chinese community is heterogeneous. Although sharing a similar ethnic and cultural background to some degree, and in some instances speaking the same language, its Chinese attendees often identify as being from Hong Kong, from Taiwan, from the People's Republic of China, or, to a lesser extent, from other diasporic communities around the world (for example, from Vietnam, Macau, and Canada). The monastery's resident monks self-identify as culturally Tibetan, but may have been born in Nepal, India, or Bhutan. All became monastics before the age of fifteen and were educated at Namo Buddha, Thrangu Rinpoche's main centre located in Nepal. Despite the resident monastic community being culturally Tibetan and the monastery being the first traditional Tibetan Buddhist monastery in the area, the Tibetan community's utilization of the monastery tends to be event-specific. They typically attend Losar (New Year) prayers, Thrangu Rinpoche's ritual empowerments (Tib. wang), and specific death rituals performed for a member of their ethnocultural community. At the Monastery, all ritual chanting is done in Tibetan. Teachings are usually given in Tibetan, then translated into English and Mandarin.

The Monastery's outreach to the greater Vancouver and Canadian communities has been limited. Lama Pema connected the monastery with other Kagyu teachers across Canada to form the Karma Kagyu Association of Canada (KKAC), a loose affiliation of Canadian Kagyu centres. KKAC was responsible for hosting the North American Kagyu Monlam ("Great Prayer Festival”) every two years and for organizing H.H., the 17th Karmapa Ogyen Trinley Dorje's first visit to Canada in 2017, but will likely be dissolved by the end of 2018. Locally, the Monastery makes food donations to Richmond's Food Bank and the Monastery participates in Richmond's Highway to Heaven Association's meetings and events. However, the monastery's principal activities are directed to serving its own members and attendees; its focus remains inwards. If using Alexandre Soucy's method of categorizing North American Buddhist centres, Thrangu Monastery Canada's orientation may be best described as parochial yet responsive to localizing forces, such as the cultural needs of its community members (Soucy 2014).

\section{Research Methodology}

I have been an adherent of Tibetan Buddhism (within the Karma Kagyu lineage) since 2009, a student of the 9th Thrangu Rinpoche since 2011, and a regular volunteer at Thrangu Monastery

4 Private communication with author, 2011.

5 Ethnicity Hot Facts. Available online: https://www.richmond.ca/_shared/assets/2006_Ethnicity20987.pdf (accessed on 26 August 2018). 
Canada since 2012 when my husband and I moved to Vancouver. Although my father is from Hong Kong and my maternal great-grandfather sailed to Canada from Canton province in the late 1800s, I do not speak or understand any Chinese dialect.

I obtained permission from Lama Pema to conduct this research. Afterwards, I created an online questionnaire that was distributed to Thrangu Monastery Canada's members via its email list and through one of its WeChat groups. A paper copy of the questionnaire was also available for completion. The questionnaire contained multiple-choice and open-ended questions related to dying and Medical Assistance in Dying, and gathered respondents' demographic data. Questions were in English as well as Chinese (traditional Chinese script). ${ }^{6}$ I also conducted fifteen semistructured interviews between August and October 2018, which allowed for more in-depth responses from participants. For this research, data from fifty-three respondents was analyzed. ${ }^{7}$

Two of the fifty-three respondents said they had no religious affiliation, while fifty self-identified as Buddhist (one chose not to respond to the question). Seventeen respondents were born in Canada; six were born in the United States; five were from Taiwan; six were born in the People's Republic of China; six immigrated to Canada from Hong Kong; and three were Chinese from other diaspora communities (Vietnam and Macau). The last eleven participants were born in Europe and other Asian countries. To be included in the study, participants had to have lived in Canada or the United States.

\section{Good Deaths in Tibetan Buddhism and at Thrangu Monastery Canada}

\subsection{In Preparation}

In the Buddhist tradition, dying in itself is not regarded as being a negative process or an event to be avoided or conquered. Rather, death of one's body is the inevitable consequence of having taken birth in samsara. Like all other composite phenomena, one's body is simply a compilation of parts, arising out of particular causes and conditions that will one day cease as soon as enough of the causes and conditions that resulted in its appearance cease. However, death of a physical body does not coincide with cessation of the multiple consciousnesses which are designated as the mind. ${ }^{8}$ In the Tibetan tradition, for unenlightened beings, one's consciousnesses continue the process of disengaging from the body for three days following the body's physical death, after which the stream of consciousness enters a bardo stage. ${ }^{9}$ Typically after spending forty-nine days in the bardo, one will take rebirth in one of the six realms of samsara. Enlightened beings deeply understand and experience the illusion of samsara, and so free themselves from the cycle of samsara altogether.

While death is inevitable for ordinary (that is unenlightened) beings, even a natural death can be a painful process not just because of the physical pain that might be involved, but because of the mental pain that arises when one can no longer hold onto the illusion of a permanent or inherently real self (Karma 2006, p. 156). According to one prominent Karma Kagyu teacher, when the mind and body's survival is no longer tenable, fear of death results (Khentin 1996). Decisions made during life, including those made at the end-of-life, affect the merit attained at death (McCormick 2013). As a result, for Tibetan Buddhists, preparing for one's death is crucial as this impacts one's experience of the bardo and potentially one's rebirth. Preparation

6 Thank you to Jeff Chao for translating the questionnaire and to George Larm for translating Chinese responses into English for me.

7 According to the Monastery's office staff, over 400 addresses are on its regular email list. Regular attendees, where attendance is $>/=1$ week, is approximately $30-40$ individuals. With this research, fifty-four questionnaires were returned to me, and three more individuals were interviewed one-on-one. I excluded data from four respondents, as they have not lived in Canada or the United States.

8 Depending on tradition, according to Buddhist scholars, an unenlightened mind can be composed of six or eight consciousnesses.

9 Dzogchen Ponlop Rinpoche explains in Mind Beyond Death that the bardo can be analyzed and segmented into different relative stages. Here in this paper, I am referring to the bardo stage that one experiences between one's death and one's next rebirth. 
may include cultivating tranquility and wisdom through contemplation, meditation, and visualization during ritual prayers and chanting. Tibetan Buddhist meditators seek to remain calm at the time of death because the quality of their consciousness at the time of death determines the quality of successive moments through the bardo to one's rebirth. Consequently, practices for dying mindfully were developed to even possibly enable a practitioner to understand his/her true nature of mind at the moment of death, which could lead to liberation. (Karma 2006, p. 103)

The monastery's teachers provide formal teaching sessions throughout the calendar year, and the topic of death and impermanence features prominently; it has been included in every three-day teaching event since the monastery's opening in 2010. In addition, all Tibetan Buddhist prayer rituals performed at the monastery involve contemplating impermanence, or praying for one or others' positive rebirths. ${ }^{10}$ It was therefore expected that many of the Monastery's members would integrate Tibetan Buddhist ideas of a good death into their answers on my questionnaire. When asked what "dying well" meant to them, eleven respondents were clear that this entailed having full consciousness and awareness of the dying process. For them, clarity of mind was important. These answers were coupled with the idea of accepting death, having a calm or peaceful mind, being able to remember the buddhadharma, having no attachment or worries, and/or being able to meditate. For example, four people stated that dying well meant retaining calmness of mind regardless of the external chaos or violence that may be surrounding them at the moment of death. They believed that suffering from mental or physical pain was not necessarily an ordeal if they maintained mental stability. They hoped that the internal tranquility they cultivated throughout their lifetimes could be used at the time of death. Their answers corresponded well with Tibetan Buddhist teachings, as explained above.

However, some respondents' answers were not rooted in religious teachings alone. Several reflected differing sociocultural attitudes about dying well. Chinese respondents frequently replied that a good death was one without illness. Three self-identified Buddhists from Hong Kong and the People's Republic of China believed that dying well was dying naturally during sleep at an advanced age, without sickness. A fourth person answered that a quick death was most desirable. Although the notion of a painless and fearless death was not unique to Chinese respondents alone, they were the only ones to suggest that dying while sleeping was optimal. They suggested that this was the best guarantor of dying without physical or mental pain. One person continued to say that the best deaths were when both external and internal (mind) environments were undisturbed. Physical agony was especially undesirable because it would most likely result in mental suffering. By dying in one's sleep, one might avoid physical discomfort as well as any warning of the impending death, and thus he or she could die without fear.

Idealizing death during sleep is contrary to Tibetan Buddhist teachings, where full mental capacity and awareness at death is most desirable. The notion that dying in one's sleep is optimal appears to be drawn from Chinese social philosophy. One of the respondents informed me that for the Chinese, this was the best death, "peaceful, easy, you just fall asleep and die, you don't even know you'll die". According to researcher $\mathrm{Li} \mathrm{Bin} \mathrm{Li,} \mathrm{"In} \mathrm{Chinese} \mathrm{culture} \mathrm{as} \mathrm{a} \mathrm{whole,} \mathrm{the} \mathrm{topic} \mathrm{of} \mathrm{death} \mathrm{is} \mathrm{generally} \mathrm{taboo}$ ... The maintenance of hope is considered very important in the care of the dying, as hope prevents suffering by avoiding despair" (Li 2013). Therefore, for these individuals at Thrangu Monastery Canada, by dying naturally in one's sleep, one can avoid thinking, worrying, or despairing about death almost entirely, and avoid dying in physical or mental distress.

10 For example, the Dorje Chang lineage prayer recited at the start of teachings and pujas includes a verse on death. Also, a short aspirational prayer to be reborn in Dewachen (Amitabha's Pure Land) is often included at the end of pujas. 


\subsection{After Death: The Akshobhya Ritual}

Preparation for one's own death is not the only concern of Thrangu Monastery Canada's members; they seek to improve the lives of their loved ones as well. Ritual prayers to improve the quality of their loved ones' lives (and afterlives) are the most well-attended at the Monastery. In fact, forty-nine of the fifty-two respondents believed that prayers can and do help the deceased. The Monastery's most popular ritual is its annual weekend Akshobhya retreat, which consists of fasting, taking Mahayana sojong vows, chanting, prayers, visualizations, and a fire offering puja. Sixty to a hundred people may attend any one of the fourteen weekend sessions, but the final session that includes a fire offering is regarded as the most important. At any time before the retreat's last day, members submit their loved ones' names on sheets of paper (yellow for the deceased, white for the living). Then, on the last day of the retreat during this fire offering, the names are burned. This symbolizes overcoming negative emotions and is believed to have a purifying effect. (Akshobhya Fire Puja 2018)

Lama Pema introduced this prayer retreat to the community in 2014 after completing the retreat himself with H.H., the 17th Gyalwang Karmapa Ogyen Trinley Dorje in India. ${ }^{11}$ The ritual is believed to be especially effective for purifying karmic obscurations, freeing beings from the fear of an unfortunate rebirth, releasing beings from lower states of existence, and ultimately liberating beings from suffering. ${ }^{12}$ Lama Pema schedules the Akshobhya prayers deliberately in the middle of the seventh (Ghost) month of the Chinese lunar calendar, when it is popularly believed that spirits and ghosts are especially harmful. In following with Chinese tradition, many of the monastery's Chinese members believe that on the first of this particular month, the gates of hell are opened, allowing spirits and ghosts access to the world of the living. Historically in Chinese culture, Buddhist or Taoist prayers were requested in order to appease hungry or angry spirits and to ease the suffering of their deceased loved ones. Scheduling the weekend Akshobhya retreat during the Chinese Ghost month is an example of Lama Pema's conscious response to the predominant community's needs. When I asked members why they participated in the Akshobhya ritual every year, they answered "to honour and pay respect to our ancestors", and to appease potentially harmful spirits. It is hoped that their ancestors may even be reborn in a Pure Land because of the prayers being performed for them.

\section{Medical Assistance in Dying}

After decades of debating one's "right to die" in Canada, in February 2015, the Supreme Court of Canada's judges unanimously passed Bill C-14, which formally legalized Medical Assistance In Dying (MAID) for eligible adults with "grievous and irremediable" conditions. The government of BC explains that "MAID occurs when an authorized doctor or nurse practitioner provides or administers medication that intentionally brings about a person's death, at that person's request." ${ }^{13}$ Qualifying for MAID, a form of voluntary euthanasia, may be a complex process. ${ }^{14}$ One qualifying criteria is

11 Akshobhya is one of the five wisdom buddhas and is blue in colour. It is believed that before attaining Buddhahood, he made a strong aspiration to uproot anger. Community members have been encouraged to make similar aspirations, and participate in these ritual prayers to strengthen their resolve.

12 https://kagyuoffice.org/the-3oth-kagyu-monlam-chenmo-day-seven/ (accessed on November 2018).

13 https://www2.gov.bc.ca/gov/content/health/accessing-health-care/home-community-care/care-options-and-cost/ end-of-life-care/medical-assistance-in-dying (accessed on October 2018).

14 For example, it is not always clear both medically and legally what constitutes a "grievous and irremediable" condition. Also, a patient must find a physician who is willing and capable of providing the service. For physicians, there are medical, legal, and possibly emotional risks involved. MAID is governed by criminal law. Thus, physicians providing MAID must abide by federal, provincial, and/or territorial laws and regulations, their local hospital and clinical policies, and the Criminal Code's guidelines and safeguards. Medical Assistance in Dying: Where Do We Stand Two Years Later? CMPA. Originally published June 2018, revised November 2018. https: / / www.cmpa-acpm.ca/en/advice-publications/browse-articles/2018/ medical-assistance-in-dying--where-do-we-stand-two-years-later (accessed 15 November 2018). 
obtaining the patient's voluntary consent; a patient must be capable of consenting at the time their request for MAID is made, as well as immediately before the procedure, and the patient's death must have become reasonably foreseeable. In addition, patients must have been informed of alternative means available to alleviate their suffering, including palliative care. ${ }^{15}$ It appears that public support for MAID is currently widespread in every region of the country. Polls published following the ruling reported that $78-85 \%$ of Canadians supported the passing of Bill C-14. ${ }^{16,17}$ In the province of BC, where Thrangu Monastery Canada is located, $84 \%$ supported MAID; $58 \%$ reported that they "strongly approved" the ruling, while $28 \%$ approved "somewhat." 18 Approximately 14\% of Canadians disapproved of legalizing MAID (7\% strongly so).

Prior to conducting this study, I assumed most members of Thrangu Monastery Canada would be opposed to this Supreme Court ruling based on their religious beliefs. There is no global governing or regulatory body for Buddhists, no one Buddhist tradition has clear doctrinal authority over others, there is no singular or distinctive Buddhist bioethics from either a historical or Buddhist point of view, nor are there official fixed positions with respect to contemporary bioethical issues (Hughes 2007, p. 127). Yet, all forms of euthanasia (literally, meaning "good death") appear to be contrary to the widely accepted Buddhist principle of nonharm (Skt. ahimsa). Buddhists may be encouraged to contemplate death, but voluntary euthanasia is regarded as suicide, and suicide is not valorized. In fact, Buddhist scripture and traditions hold that suicide is a form of murder (Venerable Mettananado Bhikkhu n.d.; Hughes 2007, p. 129; Barnes 1996). The revered 11th-century Tibetan yogi, Jetsun Milarepa, is said to have contemplated suicide when the master Marpa refused to teach him the buddhadharma. It is written in his hagiography that Milarepa said,

Since I will not obtain the dharma in this life, and since I have been accumulating terrible sins, I will kill myself. When I am reborn in a future life with a precious human body, I beg that you hold me with compassion.

As I was about to kill myself, lama Ngokpa restrained me. Weeping, he said, “Layman Great Magician, don't do such a thing! You must understand that according to the tradition of Secret Mantra, the Victor's ultimate teachings, our aggregates, constituents, and the sense fields are deities. Performing transference before it's time carries the offense of killing a deity. Killing oneself is an even graver sin. Even in the tradition of the sutras, there is no worse negative act than taking one's own life." (Tsangnyon 2010)

Moreover, assisted death is inconsistent with the precepts that have been integrated into every Buddhist tradition around the world. The five precepts are interpreted as providing guidelines for skillful (or some may say virtuous) activity (Florida 2000). Each of the precepts is explicated in the Vinaya, a written code of discipline shared by Buddhist traditions and the authoritative source for Buddhist ethics (Keown and Keown 2005). Karma Lekshe Tsomo writes "Among Tibetan Buddhists, the Pratimoksa precepts are generally viewed as the foundation of ethics and there is little support for the idea of assisted suicide. In most situations, although one is free to choose, suicide and assisted suicide are viewed as misguided courses of action." 19 Here, Karma Lekshe Tsomo connects accepting precepts with regulating moral and ethical conduct, where harm to others and to the self is minimized. Ethical behaviour then becomes the means for enlightenment. Lecturer and Buddhist scholar Alan

15 https://www2.gov.bc.ca/gov/content/health/accessing-health-care/home-community-care/care-options-and-cost/ end-of-life-care/medical-assistance-in-dying (accessed September 2018).

16 http://poll.forumresearch.com/post/233/6-in-10-would-consider-assisted-death-for-themselves/.

17 https://www.ipsos.com/en-ca/news-polls/eight-ten-80-canadians-support-advance-consent-physician-assisted-dying (accessed September 2018)

18 https://www.ipsos.com/sites/default/files/publication/2016-02/7140-tb1.pdf (accessed September 2018).

19 (Karma 2006, p. 129). 
Wallace explains, "the basic line of practice is actually very simple. The foundation of all Buddhist practice, and without which there is no Buddhist practice, is ethics" 20 .

Observing any or all of the precepts is not obligatory for Buddhists. At Thrangu Monastery Canada, an individual may accept any or all of the precepts, and may request a short ritual with either Thrangu Rinpoche or Dungse Lama Pema to formally demonstrate his or her commitment to the precepts. Once this person has completed the ritual with either teacher, that person is expected to observe the precepts for life. However, Thrangu Monastery Canada has no monitoring system governing the actions of lay members, and therefore no punishment is meted out by Thrangu Rinpoche or Dungse Lama Pema for breaking a precept. Although observing these precepts is not mandatory and one does not need precepts in order to act morally, the importance of ethical behaviour cannot be overstressed. The monastery's resident scholar, Khenpo Sonam, informs students during his weekend class that the cause of all suffering is unvirtuous behaviour, and the cause of liberation is the opposite, that is virtuous actions.

Damien Keown, perhaps the foremost authority on Buddhism and bioethics, notes, "Euthanasia is rejected by most Buddhists as contrary to the First Precept, which prohibits intentional killing" (Keown 2005). There are five conditions that, when met, constitute the act of killing. They are: (i) the presence of a living being; (ii) the knowledge that the being is living; (iii) the intent to kill; (iv) the act of killing; (v) the resulting death (Saddhatissa 1970). According to the Vinaya, Keown says, killing is irreligious.

Should any monk intentionally deprive a human being of life, or look about for a knife-bringer [to help him end his life], or eulogise death, or incite [anyone] to death saying "My good man, what need have you of this evil, difficult life? Death would be better for you than life,"-or who should deliberately and purposefully in various ways eulogise death or incite [anyone] to death: he is also one who is defeated [in the religious life], he is not in communion. (Keown 2005)

Taking life intentionally constitutes in immoral, harmful act and one cannot escape the negative karmic consequences of killing, even if one does so with a benevolent attitude ${ }^{21}$. Because killing necessarily entails causing harm to another or one's own body, negativity within one's own consciousness is generated, resulting in future suffering for both the killed and the killer. "In taking this [first] precept, a Buddhist recognizes his relationship with all living things, a relationship which is so close that the harming of any living creature is inevitably the harming of himself. The Buddha taught the advisability of comparing one's own life with that of other beings: 'Everyone fears violence, everyone likes life' comparing oneself with others one would never slay or cause to slay." (Saddhatissa 1970)

Due to the Buddhist belief in reincarnation, the rationale for supporting MAID decreases even further. Instead of suffering ending with a body's physical death, it is thought that suffering continues from one life to another, and will only be uprooted with ignorance if completely vanquished. Therefore, bodily death does not permanently resolve the suffering one experiences. In fact, euthanasia may even augment future suffering for the patient and for anyone who supported the patient's death because taking life is such a negative act. Thus, because of the belief in reincarnation, and the extreme negative effects of killing another being, theoretically, Buddhists reject all forms of euthanasia because they reject the assumption that the patient's death is better than his or her life.

20 Alan Wallace as quoted by (Luisi 2008).

21 "Life" in the Buddhist context includes all individuals, creatures, and beings (such as people, animals, gods, demi-gods, and so forth) with consciousness, irrespective of a being's form and size. 


\subsection{Respondents' Views on MAID}

Contrary to my initial assumption, only eight of TMC's fifty-three respondents, or $15 \%$, were completely against medical assistance in dying. ${ }^{22}$ Two did not provide their reasons for being against MAID, but two others alluded to it being unnatural. Even for one respondent who thought "dying well" meant a painless death, MAID was unacceptable on the basis that it was not natural. Four others referred to their Buddhist beliefs for their position. Of these four, two were born in Hong Kong and two were born in Canada. The first wrote, "I believe in buddha teachings about the Reincarnation. There must be a reason and time for you to be in a human in this life and of course, there would be a time and reason to be finished in this life. Should go with the through (cause and effect), if we force the issue (Euthanasia), just bring us more pain and suffering in next life. Life is not just one time, its continuous." The second cited, "it is very bad. It is suicide which is murdering oneself. Not only that you are also causing the people assisting you to accumulate bad karma. Your terminal illness is a part of your karma." The third person opposed to MAID referred to the belief that physical and mental suffering purifies the negative karma that one has accumulated over limitless lifetimes. The respondent wrote, "one should live and purified this life negative karma. If not purified this life then continues next life." For this individual, MAID is unacceptable because an early death prevents the purification necessary for the patient's improved future.

The last of the eight "against" respondents, a practicing family physician, did not agree with euthanasia for medical as well as religious reasons, which in his mind were inseparable from one another. He felt that, as a Buddhist and as a physician, he made a vow to do no harm. Although he refers patients requesting MAID appropriately, in his experience, it is often the artificial prolonging of life and the fear of pain that drive people to seek MAID. He argued that with more comprehensive education on palliative care and on the advances in pain medication, perhaps fewer individuals would feel that their only recourse to avoid physical and mental torment is death. Instead, they may consider taking medication that could control their symptomatic suffering as they wait for natural death. In his opinion, this would necessitate greater discussions between medical professionals, families, and patients on end-of-life care.

Twenty-three respondents (44.2\%) expressed limited support for assistance in dying. Sixteen respondents felt it was an individual's decision to seek and use MAID, and a further seven answered that voluntary euthanasia was acceptable only in very specific circumstances or when the physician and family have very specific intentions (such as compassion for the dying or when pain is too severe for the patient to handle). For this group, support for MAID was generally reluctant/hesitant, and can most accurately be described as against the concept of voluntary euthanasia as a whole but not necessarily against Canadian law and practice, or against an individual's right to choose. Five of these respondents stated explicitly that they would not choose MAID for themselves. Another four people answered, to some extent, that killing went against Buddhist doctrine, but medically assisted death may be preferable in cases of extreme pain. This should be assessed on a case-by-case basis. This group of four included two monks who have completed Buddhist monastic postsecondary education in Nepal, a Tibetan doctor in the US, and a Canadian-born member who meditates and studies daily.

Fourteen respondents answered more favourably in support of MAID (26.9\%). Eleven of the respondents were born and educated in Canada, the US, or the UK..$^{23}$ One person, an individual born in Shanghai, acknowledged that while assisted dying goes against Buddhist teachings, s/he "totally agreed" with it because humans "should have the right to decide their own life". This concern for an individual's right to choose was echoed by a second respondent: "It is a great idea, it gives people a chance to choose their way to their life and, to be at peace." Four others supported MAID on the

22 The author is aware of the relatively small sample size, so percentages contained in this paper may not be reflective of the community as a whole.

23 Two respondents were born in Taiwan and the last was born in Shanghai. 
grounds of compassion, to end one's suffering, and/or to not be a burden on loved ones. The only nonreligiously affiliated individuals included in this analysis also strongly supported MAID. The final group of respondents either chose not to answer this question, or were unsure/had no opinion/neither for nor against MAID.

\subsection{Supporting MAID at TMC-Balancing Autonomy, Wisdom, Compassion, and the Vinaya}

Over $71 \%$ of TMC's respondents support medical assistance in dying, which is a greater percentage than I expected. Support amongst this group's members is not universally strong, but it is worth noting that they are not opposed to MAID as it stands in Canadian law and practice. Their reasons for supporting MAID can be grouped into three general categories: (1) autonomy and noninterference; (2) wisdom; and (3) compassion.

\subsection{Individual Choice and Noninterference}

The most frequently expressed reason in support of MAID (or at least not in opposition to it) was that it was an individual's decision to make. Only three respondents framed the issue in terms of a person's "right" to choose. More often, respondents said it was not their place to interfere and/or that we should respect the integrity of personhood. Statements such as "respect one's choice", and "if a person truly wants to die, that is their choice" were common. Likewise, one respondent answered, "I think we should support life but not judge those who are suffering," and another replied "I think it's a very personal decision. I don't object it, but it would not be my choice if I can help it."

Interestingly, three members from this "limited support" group claimed that, in Chinese culture, voluntary euthanasia is unacceptable. However, because they live in Canada, they believe that the practice was inevitable and they should not interfere with the decision another person is making. One said "for Chinese, you cannot do this ... But I respect a person's choice." The second offered this explanation: "in Chinese, all religions have the Chinese character for 'family' at the end, like Taoism, Buddhism. So you can't separate religion from family, family is in the religion ... To take your life is not thinking about family. Your mother and father gave you that life. Suicide is a selfish choice ... But in Canada, it maybe can't be stopped. This is an individual society." He later added that MAID was acceptable for him IF all family members agreed to the person's dying in this way.

Two respondents are from Hong Kong and the third was born in the People's Republic of China, where all forms of euthanasia remain illegal. Their answers reflect conflicting values between their Chinese heritage and Canadian society. Whereas bioethical debates in Canada center around the autonomy of an individual, Chinese bioethics is embedded in a Confucian way of life and, as a result, family-oriented autonomy and social harmony are prioritized (Li 2013). This confirms Bülow's findings that the importance of patient autonomy in the Western (Christian) world is not necessarily an issue among other ethnic and religious groups (Bülow et al. 2008). However, it should be noted here that none of the Taiwanese respondents mentioned maintaining family harmony in such a time; supporters all believed that to use MAID or not was an individual's choice. The answers of these three TMC respondents demonstrate that their cultural upbringing impacts their views of MAID more so than their religious beliefs. However, it appears that they do not seek to impose their beliefs on the greater Canadian society in which they live. As a result, they seem to be attempting to accept the practices of the dominant society, regardless of their personal feelings on the matter.

For all of the respondents in this group, being unable to justify imposing their own beliefs on others suggests an attitude of noninterference. A primary cause for the prevalence of this attitude cannot be identified at this time, but it does seem to, coincidentally or not, reflect Thrangu Rinpoche's own common motto: "If you can help, help. If you can't help, at least don't harm."

\subsection{Wisdom}

Several respondents acknowledged that while voluntary euthanasia was undesirable in principle, in extenuating circumstances, MAID could be the wisest course of action. Three stated that if a person 
could not cope with acute suffering and distress, the mind would not be calm or relaxed, making it difficult for the patient to transition to the next life. According to one monk, he said that the issue was a difficult one because "strictly according to Buddhism, [active euthanasia] is not allowed. It is considered a black action even if all four requirements are not met ... Suffering follows you to the next life." Moreover, he said, ordinary people cannot have a purely disinterested, compassionate motive, thus tainting the action of killing further. Yet, he acknowledged that in some cases of extreme suffering, it would be better to allow the patient to die.

In reference to killing being possibly the wisest course of action available, he and another member recounted a story from one of the Buddha's past lives. There are variations to the story, but generally, it is said that he was the captain of a ship carrying 500 passengers. Amongst his passengers was a thief who was planning to murder all 500 passengers on board. The captain, being a highly realized bodhisattva, was omniscient and completely compassionate. As a result, the captain knew the thief's murderous plans. Because the captain foresaw that the would-be murderer would suffer greatly from the karmic consequences of killing so many people, and he foresaw the victims' future suffering if they were to be attacked, the captain killed the thief pre-emptively. Saving all others on board demonstrated the captain's wisdom and pure compassion. These two respondents used this story to communicate that killing, if performed out of wisdom and compassion that saved lives, could be the most appropriate of undesirable options. However, one added the following caveat: "I wouldn't be able to judge myself if [MAID] is alright for a person. I wouldn't be able participate [in MAID] because I'm not a bodhisattva. But I can't tell who is and who isn't [a bodhisattva], so maybe, in those cases, when a bodhisattva is involved, MAID is ok, maybe is less of a negative action."

For this group of respondents, they believed that whether MAID was an appropriate solution to deal with a patient's suffering should be judged on a case-by-case basis. These findings echo those of Michael Barnes, who noted that when confronted with the issue of euthanasia, some Buddhists have avoided taking a fundamentalist position, contending that the Buddha-mind is not fixed on a singular position. They therefore attempted to deal with problems as they arose (Sumedho 1996). Similarly, Robert Florida noted that neither a nihilistic position (denying karmic consequences) nor an eternalist position (believing in the Buddha's "commandments") are thought to be helpful or correct. (Florida 2000)

\subsection{Compassion}

For some respondents, MAID was acceptable on the grounds of compassion, and the futility of extreme suffering was questioned. For example, one person wrote, "It's a blessing. Why should people suffer?" Another similarly answered, "sometimes to let someone who is really really sick, seems like a kindness so let him die." In accordance with Buddhist teachings on generating a positive motivation, for two individuals, having a compassionate attitude lessens the severity of the act. One explained, "As a Buddhist killing any being is considered nonvirtuous action or downfall. But if a person kills with an intention of benefiting them or bring satisfaction to their loved one through their death then should be acceptable. Even though there will be a downfall of killing but his intention is far stronger of bringing benefits to others." A few participants said that maintaining a pure motivation was rare, but would not rule out the possibility entirely. It was especially those individuals who defined dying well as dying consciously without pain were the most supportive of MAID.

This data contrasts with Damien Keown's conclusion that in Buddhism, compassion may be a morally good motive but it does not justify whatever is done in its name. Keown refers to a passage in the Vinaya that describes an instance of "mercy killing" where a monk was said to have participated in ending another man's life. Although the monk wanted to spare the dying man unnecessary pain, the fifth-century commentator Buddhaghosa declared the monk's act to be immoral. Buddhaghosa explained that despite the monk's benevolent attitude, the aim was to destroy life, which in essence is a non-virtuous action. (Keown 2005) 
Thrangu Monastery Canada's members apparently rate the absolutory power of compassion much higher than either Buddhaghosa or Keown. This may be because they self-identify as practitioners of the Secret Mantra and Mahayana vehicles, where it is said that compassionate intentions supersede bodily actions in importance, and where the bodhisattva ideal is upheld. For Mahayana practitioners, bodhisattvas are believed to be insightful enough to ascertain whether their intentions are tainted by selfishness or not. Acts that are ordinarily immoral, such as killing, would be excusable if such acts alleviated suffering, and if the bodhisattvas who committed the act were willing to suffer the karmic consequences of the said actions (Hughes 2007, p. 128). Therefore, by having a pure motivation, one can avoid all misdeeds (Karma 2006, p. 130). Keown's sole consideration of the Vinaya and one fifth-century commentator is too limited if examining today's living Buddhist traditions.

A full range of opinions regarding MAID was found in the answers of Thrangu Monastery Canada's participants, from strongly opposing the practice to strongly supporting it. Elsewhere, it was noted that Buddhist bioethical discussions center around the conflict between the moral precept of not taking life, the ethical implications of the doctrines of no-self, karma, and rebirth, and the practice of compassion. The debate at Thrangu Monastery Canada was similar in this regard, but with the addition of an emphasis on autonomy (Barnes 1996; Karma 2006, p. 19) In Buddhism, wisdom and compassion are said to be the two wings of a bird. Just as a bird cannot fly with one wing alone, meditation practice is not sustainable without both wisdom and compassion. For a portion of Thrangu Monastery Canada's respondents, legally MAID is acceptable if wisdom and compassion are involved. However, for the majority of this study's participants, even if wisdom and compassion were not present in all cases of assisted dying, it probably could not justify their interference in another individual's affairs. The autonomy of the person should be respected. Overall, most of the respondents weighed these three values-autonomy, wisdom, and compassion—much more heavily than the scriptural proscriptions and moral absolutes existing in the Vinaya.

\section{Conclusions}

How does one achieve serenity before, during, and after death, in order to eventually escape the endless cycle of birth and death forever? If one is suffering miserably, can serenity be achieved with medically assisted death? At Thrangu Monastery Canada, death and impermanence are subjects of frequent contemplation. Here, it became apparent that members draw on an arsenal of Tibetan Buddhist philosophy, rituals, prayers, and meditations, as well as their own cultural knowledge, in an attempt to answer these questions. While it was generally acknowledged that a good death is a peaceful one, defining and finding it are being shaped by a multiplicity of forces. Respondents relied on a myriad of Buddhist notions (such as dying mindfully with full awareness) and cultural ideas (such as dying painlessly in sleep) when explaining what it meant to die well. Similarly, when offering their opinion about Medical Assistance in Dying, different religious and secular values were expressed. Members were generally weighing the importance of autonomy (individual or socially anchored), compassion, and wisdom with the Vinaya's behavioural injunctions. Contrary to what a strict scriptural analysis of the Vinaya might suggest, the majority of Thrangu Monastery's respondents supported MAID at least to some degree, or in some circumstances. Thus, the source of the members' views concerning ethical behaviour cannot be traced to the Vinaya or to their Pratimoksha vows alone. For them, maintaining moral absolutes was less important than not interfering with another's agency, and less important than being able to view each instance of suffering with discerning wisdom and compassion.

Funding: This research received no external funding.

Conflicts of Interest: The author declares no conflict of interest. 


\section{References}

Akshobhya Fire Puja. 2018. Available online: http:/ / www.kagyumonlam.org/index.php/en/2017-02-12-16-2611/in-pictures-archives/244-kagyu-monlam/in-pictures/2018/1388-akshobhya-fire-puja-2018 (accessed on 1 November 2018).

Barnes, Michael. 1996. Euthanasia: Buddhist Principles. British Medical Bulletin 52: 369-75. [CrossRef] [PubMed] Bülow, Hans-Henrik, Charles L. Sprung, Konrad Reinhart, Shirish Prayag, Bin Du, Apostolos Armaganidis, Fekri Abroug, and Mitchell M. Levy. 2008. The World's Major Religions' Points of View on End-of-Life Decisions in the Intensive Care Unit. Intensive Care Medicine 17: 423-30. [CrossRef] [PubMed]

Florida, Robert. 2000. Buddhism and Abortion. In Contemporary Buddhist Ethics. Edited by Keown Damien. Surrey: Curzon Press, p. 138.

Gampopa. 1998. Jewel Ornament of Liberation. Edited by Ani K. Chodron. Translated by Khenpo Konchog, and Gyaltsen Rinpoche. Ithaca: Snow Lion Publications.

Howarth, Glennys, and Margot Jefferys. 1996. Euthanasia: Sociological Perspectives. British Medical Bulletin 52: 377. [CrossRef]

Hughes, James. 2007. Buddhist Bioethics. In Principles of Health Care Ethics, 2nd ed. Edited by Richard Edmund Ashcroft, Angus Dawson, Heather Draper and John McMillan. Hoboken: John Wiley \& Sons.

Jamgön, Kongtrul Lodrö Thaye. 2014. The Ninth Karmapa Wangchuk Dorje. In The Torch of True Meaning: Instructions and the Practice Text for the Mahamudra Preliminaries. Woodstock: KTD Publications and Kagyu Monlam.

Karma, Lekshe Tsomo. 2006. Into the Jaws of Yama, Lord of Death: Buddhism, Bioethics, and Death. Albany: State University of New York Press.

Keown, Damien. 2005. End of Life: The Buddhist View. Lancet 366: 952-55. [CrossRef]

Keown, Damien, and John Keown. 2005. Killing, karma and caring: Euthanasia in Buddhism and Christianity. Journal of Medical Ethics 21: 265-69. [CrossRef]

Khentin, Tai Situpa. 1996. Talk on the Bardo (Death and Dying). Scotland: Kagyu Samye Ling, Eskdalemuir.

Li, Bin Li. 2013. Clinical Review: Ethics and End-of-Life Care for Critically Ill Patients in China. Critical Care 17: 244. Available online: https://www.ncbi.nlm.nih.gov/pmc/articles/PMC4057346/ (accessed on 12 November 2018).

Luisi, Pier Luigi. 2008. The Two Pillars of Buddhism: Consciousness and Ethics. Journal of Consciousness Studies 15: 84-107.

McCormick, Andrew J. 2013. Buddhist Ethics and End-of-Life Care Decisions. Journal of Social Work in End-of-Life and Palliative Care 9: 209-25. [CrossRef] [PubMed]

Saddhatissa, Hammalawa. 1970. Buddhist Ethics: Essence of Buddhism. London: George Allen \& Unwin Ltd.

Soucy, Alexander. 2014. Buddhist Globalism and Canadian Buddhism. In Flowers on the Rock: Global and Local Buddhisms in Canada. Edited by John S. Harding, Victor Sogen Hori and Alexander Soucy. Montreal and Kingston: McGill-Queen's University Press, pp. 25-52.

Sumedho, Ajahn. 1996. As quoted in Barnes, Michael. Euthanasia: Buddhist Principles. British Medical Bulletin 52: 370 .

Thrangu Monastery Canada. 2018. Available online: https:/ / thrangumonastery.org (accessed on 10 October 2018). Tsangnyon, Heruka. 2010. The Life of Milarepa. Translated by Andrew Quintman. New York: Penguin Books, pp. 78-79.

Venerable Mettananado Bhikkhu. n.d. Buddhist Ethics in the Practice of Medicine. In Buddhist Ethics and Modern Society, An International Symposium. Edited by Charles Wei-hsun Fu and Sandra A. Wawrytko. New York: Greenwood Press, p. 209.

(C) 2019 by the author. Licensee MDPI, Basel, Switzerland. This article is an open access article distributed under the terms and conditions of the Creative Commons Attribution (CC BY) license (http://creativecommons.org/licenses/by/4.0/). 